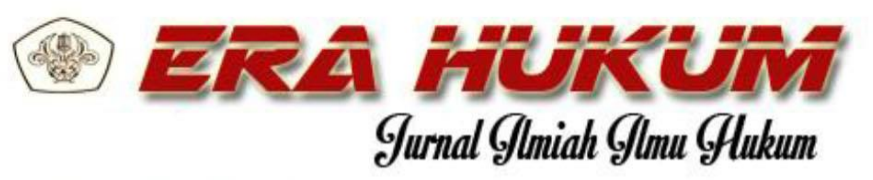

Volume 17, No. 2, Oktober 2019

ISSN 0854-8242 | e-ISSN 2581-0359

Fakultas Hukum - Universitas Tarumanagara

open Access at: wwwj ournal.untar.ac.id/index.php/hukum

Era Hukum - Jurnal Imiah Ilmu Hukum is licensed under Creative Commons Attrib ution 4.0 International License, which allows otherwiters to use, distribute, ond/or build upon this article, as long as the original work is properiy cited.

\title{
PERLINDUNGAN HUKUM TERHADAP PEMEGANG SERTIPIKAT HGB UNTUK MEMPERPANJANG DAN MEMPERBARUI HGB DI ATAS HAK PENGELOLAAN STUDI PUTUSAN MA NO 3090/K/Pdt/2017
}

\begin{abstract}
Hasni
(Dosen Hukum Agraria dan Filsafat Hukum Universitas Tarumanagara. Meraih Sarjana Hukum pada

Fakultas Hukum Universitas Atma Jaya (Hukum Pidana, 1971) dan Universitas Krisnadwipayana (Hukum Perdata, 1973), Magister Hukum pada Fakultas Hukum Universitas Indonesia (1987), Doktor (Dr.) pada Fakultas Hukum Universitas Trisakati (2012)
\end{abstract}

(E-mail: Hasni.sh9@gmail.com)

\section{Steven Ouddy}

(Mahasiswa Program S1 Fakultas Hukum Universitas Tarumanagara)

Received: 20 Agustus 2019; Accepted: 03 September 2019; Published: 29 Oktober 2019

\begin{abstract}
This research is about legal protection for holders of certificate of building use rights to extend and renew building use rights over management rights which is the main problem is how the authority of holders of certificates of building rights in extending and renewing building rights over management rights and how to protect them against Building Rights holders who have expired brut sktill occupy $q$ lanqd and builqdings. The metqhod ursed in theis stusdy is normative law, namely research that seeks to connect between legal norms that apply to the reality that exists in society. The soqurce of legal matqerial used is primarqy legqal matqerial and secoqndary legal matuerial. The research specifications used are analytical descriptive which are expected to be able to givqe a detaqiled, systeqmatic, andcomprehensive description of gall mattersrelating to Management Rights, Building Use Rights and legal protection against Rights holders to Build on Management Rights. The conclusion of this paper is that Building Use Rights over Management rights can be extended based on the applicable Law and good faith
\end{abstract}

Keywords: government regulation, laws, regulations

I. PENDAHULUAN

\section{A. Latar Belakang}

Negara Indonesia adalah negara yang berdasar atas hukum (rechstaat). Hal ini sebagaimana tertuang pada 


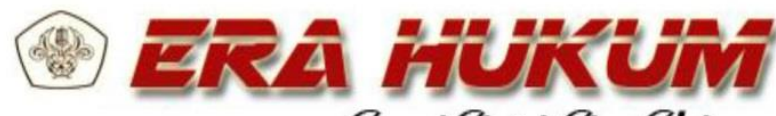

G)urnal GImiah G/mu Glukum

Volume 17, No. 2, Oktober 2019

Pasal 1 Ayat (3) Undang-Undang

Dasar Republik Indonesia Tahun 1945 yang menyebutkan bahwa "Negara

Indonesia adalah Negara Hukum”.

Berdasarkan ketentuan ini, maka

konsekuensinya adalah segala

tindakan pemerintah dan rakyat harus

sesuai dengan ketentuan hukum yang

berlaku. Hukum yang ke wuqjud

dalam peraturan perund angundan gan

berfungsi untuk memberi dasar,

menentukan arah dan tujuan yang

hendak dicapai, serta cara bertindak

bagi Negara dan aparatnya.

Aturan tentang tanah yang diatur pemerintah di atur dalam Unda ng Unda ng Dasar dan Unda ng - Unda ng. Dalam Pasal33 Ayat3 Undang Unda ng Dasar 1945 (Amandemen ke IV), yang selanjutnya disingkat dengan UUD 1945 (Amandemen ke IV) disebut kan kalo untuk bumi, air dan kekayaan alam yang udah ada di dalamnya dikuaqsai oleh negara dan dipergunakan sebesar-besarnya untuk kemakmuran rakyat. Kata "dikuasai oleh Negara" terlihat tersebut kewenangan di bidang pertanahan
Hasni \& Steven Ouddy Perlindungan Hukum Terhadap Pemegang...

dilaksanakan oleh negara yang dalam pelakasanaannya dilakukan oleh pemerintah pusat. Kalo melihar darikewenangan yang berdasarkan kewena ngan yang bersumberpada konstitusi tersebutmaka kemudianditerbitkan UUPA yang mengatur untuk keagrariaan atau pertanahan sebagai bagian dari bumi.

Ada juga pasqal yang menyebutkan Pasal2 Ayat2 UUPA dikataka bahwa Negara sebagai sendiri dikaih sama rakyatnya untuk bisa mengatur, yaitu pmbuatin peraturan, melaksanekqn, meng gunakan, lihara atas bumi,air dan ruangang kasa serta kekayaan alam yang sudah ada didalamnya.kita liat dari hak menguasai negara atasbumi, aqir dan kekay aan alam tersebut, maka kuasa atas pengquasaan dan pengturusan bidang pertanahan ada pada negara, dimana ada pada negara, dimana di bidang ek sekutif (pemerintahan) dijalankan sama 


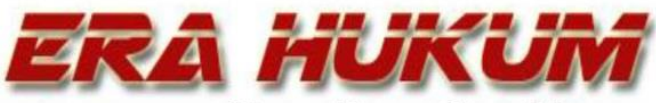 9. Irnal Glmiah G.lmu GHukum \\ Volume 17, No. 2, Oktober 2019}

Presiden atau dikasih ke kepada menteri. ${ }^{1)}$

Dalam Pasal 14 UUPAterdapat ketentquan yang ada isi wewenang pemerintah untuk tatacara danpenyelengreaan untuk per untukan, penggunanaan, persedikaan untuk pemaelihajra bumai, aiqr dan ruanqg anqkasa. Pemerintah wajib membuat rencana umum nasional (national plannimng) secara rincidan dilaksanakansesuai wewen ang yang dikasih oleh Pemerintah $^{2)}$

Untuk mengatasi dan menanggulangi masalah-masalah tersebut, penguasaan bidang tanah tersebut pun dijamin dan dilindungi oleh hukum dalam bentuk peraturanperaturan di bidang pertanahan. Jaminan hukum tersebut kemudian memberiqkrn kepastian hukum dalam bentuk hakhqak atas suatutanah. Haqhaq atas tanah memberqikn

1) Edy Ruchiyat, Politik Pertahanan Nasi onal Sampai Orde Reformasi, Edisi ke-2 (Bandung : Alumni, 1999), hlm.11.

2) Boedi Harsono, Hukum Agraria Indonesia, Sejarah Pem bentukan UUPA, isi dan Pelaksanaannya, Jilid I. (Bandung: Citra Aditya,1997), hlm.239.
Hasni \& Steven Ouddy Perlindungan Hukum Terhadap Pemegang...

wewenanguntuk mempergunakan tanah itu sekedardiperlukan untuk kepentingan yang langsungberhubungan dengan penggunaan tanah.

Pertanahan diatur di dalam Undang-Und ang Nomor 5Tahun 19 60 tentang Pokok Agrqaria, yang selanjutnya disebut sebagai UUPA, yang dilengkapi dengan peraturanperaturan lain selain UUPA dalam rangka mengatur halq yang berkaitan dengan tanahsecara lebih spesifik dikarenakan oleh dampak perkembangan zaman yang menyebabkan masalah-masalah mengenai tanah semakin menjadi kompleks. Salah satu peraturan yang berguna untuk membantu UUPA adalah Peraturan Pemerintah Nomor 24 Tahun 1997 tentang Pendaftaran Tanah. Peraturan tersebut mempunyai fungsi untuk mengatur mengenai peralihan hak atas tanah, sehingga memudahkan masyarakat dalam menempuh proses hukum yang benar dalam mengalihkan hak atas tanah dan memperoleh penguasaan atas tanah. 


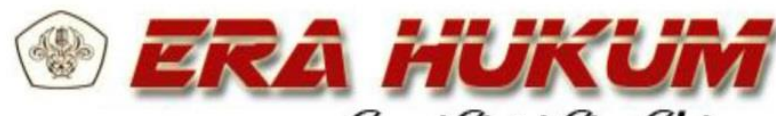

G)urnal GImiah G/mu Glukum

Volume 17, No. 2, Oktober 2019

HGB ddi atas tanah Negara atau di tanah Hak Pengelolaan itu bisa terjadi saat udah didaftar oelh pihak Kantor Pertanahan kalau di Pasal23 ayatw2 PP No40 Tahun 1996 hgb atas tanah Hak Milik bisa aha jadi kalo ada pemberian oleh pemegang Hak qilik, denganAk ta yang dib uat oleh Peja bat Pem buat akta qanah. Pasal24 ayat1 PP 40Tahun 1996 Jadi HGB itu sebetulnya bisa ada kalo ada dibuatnya Akta oleh Pejabat Pembuat Akta Tanah beri ketentuan tentang pemberian HGB oleh pemegang gak nilikq atas tanah dimaksud tapi itu akan menglikat pihak keatig kalo ud didaftaqrkan di Kantor Pertanahan.

peraturan yang berguna untuk membantu UUPA adalah Peraturan Pemerintah Nomor 24 Tahun 1997 tentang Pendaftaran Tanah. Peraturan tersebut mempunyai fungsi untuk mengaturbnmengenai perali han hak atastanah, sehingga me mudah kan masyarakat dalam menempuh proses hukum yang benar dalam mengalihkan hak atas tanah
Hasni \& Steven Ouddy Perlindungan Hukum Terhadap Pemegang...

dan memperoleh penguasaan atas tanah.

Istilah wanprestasi berasal dari Bahasa Belanda yang berarti prestasi buruk jika dibandingkan dengan "wanbeheer" yang berarti penguasaan buruk "wandaad" perbuatan buruk. ${ }^{3)}$ Wanprestasi dapat diartikan sebagai tidak terlaksananya suatu prestasi karena kesalahan debitur baik karena kesengajaan maupun karena kelalaian.Wanprestasi yang terjadi dalam perjanjian tidak selamanya karena suatu kesalahan dari salah satu pihak, melainkan ada kalanya karena suatu permasalahan atau kendala dalam pelaksanaan perjanjian sewa menyewa yang diadakan itu sendiri. ${ }^{4)}$

HGB atastanah Negyara atau atas tanahHak Penqgelolaan, terjadti kalo udah didaptarin yang dlkukan $\mathrm{d}$

\footnotetext{
3) R.subekti (a), Hukum Perjanjian, (Jakarta : Intermasa, 2005), Hal. 45.

4) Syafira Mahila dan Nur Fauzia, "pelaksanaan perjanjian Sewa Tempat Usaha Antara Pedagang Angso Duo dengan Pemerintah Daerah Kota jambi”, Jurnal Ilmiah Universitas Batanghari Jambi, volume 10 No.1 tahun 2010, Hal. 41.
} 


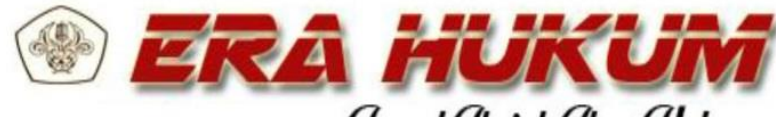

G)urnal GImiah G/mu Glukum

Volume 17, No. 2, Oktober 2019

Kantor Pertqanahan. Pasal 23 ayat (2)

PP No. 40 Tahun 1996 Hgb atas tanah

Hak M ilik, terjadi dengan pem berian

oleh pemeqgang HakMilik dengan

akta yang dib uat olehpejabat

pembuataktatanah. Pasaql 24ayat1 PP

No40 Tqahun 19 96. Jadi Hgb itu bisa

tim bul dan ada, kalo diwaktu dibuqat

nya akta oleh pejab at oembuat akta

yanah yang me muat ketentu antent

ang pemberian .Berdasarakan

ketentuan UUPA yang memiliki sifat

nasional baik formal ataupan material

formal nasional karena dibuat oleh

pemblentuk UU di Indonesia,dibuat

di Ind1onesia dan disusun di

Indonesia dan sebagai material

nssional karena berisi ketentuan

ketentuan yang sesuai dengan asas

asas dan kepeentingan nasional ${ }^{5}$ jika

demikian adanyaberarti bahwa

didalam pasal2 ayat4 Undqang

undaqng pokiok agrarian nomor 5 tah

un 1960subjek ttg hakpengelolaan

adalah badan pengawasan yang berupa

depar termen jawatran atau

5) Effendi Perangin, Hukum Agraria Di Indonesia (Jakarta: Rajawali pers,1991) hlm 200
Hasni \& Steven Ouddy Perlindungan Hukum Terhadap Pemegang...

daerahswantantra. Sedangkan

sebelumnya olee pp nomorqi tahun 1953yang menjadi subjek hak penguasaan ${ }^{6)}$

Menurut R. Atang

Ranoemihardja sebetulnya pengertian hak pengeglolaan itu berisikan mengenani suatu pengertian hak atastanah yang dikua sainegara juga cuma bisa untuk dibe rikan unt badanhukum pemerintahatau pun pemerintahdaerah bisa aja untuk usaha uasah sendiri atau juga kalo ada untuk ke pentin gan pihak ketiga right toot use dari hak pengelolaan itu sebedulnya justruk bersipat kumulatif maksuqn tanah yang dipeganga akan langsung olehnegara itu sendiri akan dikasihin melalu hakpengelolaan kepada suatu badan hukum pemeriqntah ato pemda setempat untuk kepentingan pelakasanaan tugas tugasya didalam PMA nomoor 9 tahnu 1965 yang udah ksih wewenanguntuk merencanakan per untuk an dan pengun aan tanah yang bersanfkutan,

6) Ramli Zein, Hak Pengelolaan dalam Sistem UUPA, Cetakan ke - 1. (Jakarta: Rineka Cipta, 1995, hlm. 65 


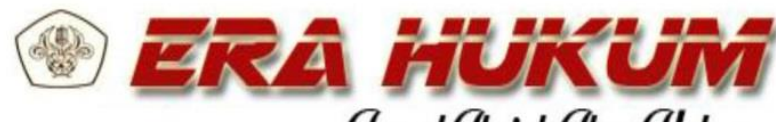

G)urnal GImiah G/mu Glukum

Volume 17, No. 2, Oktober 2019

menggunkan tanah itu buat keperluan pelaksnanantugasnya menyerhakan bagqian dari tanah ini kepada pihak ketiga dengan hak pakai yang berqjangka tahum dapatk anuang pembasukan dan atu uan $\mathrm{g}$ wajib

Namun dalam hukum hakpengelolaan telah diterapkan pada pasal 2 ayat 4 yang menyatakan bahwa hak menguasai dari negara tersebut diatas atas pelaksnaannya dapat dikuasakan kepada daerah daerah swantantra masyarakat hukum adat sekedar diperlukan atau tidak bertentangan dengan kepentingan nasional, menurut ketentuan ketentuan pemerintah didalam PMA nomors 9 tahun 1965 tentnag pelaksanaan konfersi ha katas tanah near dalam pasal2 ayta1 huruf a terdapat isian ewenang mengenai rencana peruntukaan danengg unaan tanah yang bersangkutan menggunakan tanahte rsebut utnuk pelakasnana usahaannua, menyerhakan bagian itu kepada pihakketiga persyaratan yang ditentikan oleh pihakk etiga.
Hasni \& Steven Ouddy Perlindungan Hukum Terhadap Pemegang...

Yang booleh mempunyai hgb itu kalau didalam pasal 36ayat1 Wargqa Negqara Indonesia dan juga untuk badanhukum yang di diri kan menurut hukum indoensia dan berke duduk an di Indonesia 7) hgbangunan sebenarnya dpat saja dialihkan mellaului instansi instansi yang ada yaitu instansi yang berwenang memberi izin pemindahan hak guna bangunan itu adaalah bupati walikota kepala daerah yaitu sepanjang hak guna banggunann itu diatas tnah negara dan berpindah dari pemegang hak wni atau badan hukum yang bugan bermodal asing.

Di Pasal 21 dan Parsal 41 didalam Peraturan Pemerintah Nomor 40 Tahun 1996 dikatakan bahwa diatas tanah Hak pengelolaan itu sebenarnya bisa saja dapat dikasihin HakGunaBangunan dan HakPakai tapi Sementara itu, haqk - haik atastanah yang ada dlam di Pqasal 16 UUPA tidak secara eksplisit menyebutkan dasar dan landasan hukum yang mengatur tentang hak pengelolaan, 


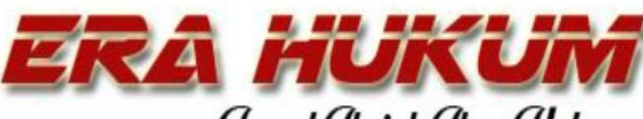

Gurnal G/miah G/lmu Glukum

Volume 17, No. 2, Oktober 2019

namun demikian hak pengelolaan dapat digolongkan sebagai hak - hak lain yang akan dan yang harus ditetapkan dengan undang - undang ternyata sampai sekarang belum ada undang - undang yang mengatur tentang hakpengeloalaan sampe saat ini itu sebagaiberikut:

1. Undnang - Undnang Nomor 5Tahun19 60 tentang Peraturan DasarPokok - PokokAgraria;

2. Peraturan Menteri Agraria Nomor 9 Tahun 1965 tentang Pelaksanaan Konversi Hak Penguasaan atas Tanah Negara dan ketentuan - ketentuan tentang Kebijaksanaan Selanjutnya;

3. Peraturan Menteri Agraria Nomor 1 Tahun 1966 tentangPendaftaran Hak Pengelolaan;

4. Peraturan Menteri Agraria Nomor 6 Tahun 1972 tentangPelimpahan Wewenang Pemberian Hak Atas Tanah;

5. Peraturan Menteri Agraria Nomor 5 Tahun 1974 tentang
Hasni \& Steven Ouddy Perlindungan Hukum Terhadap Pemegang...

Ketentuan - Ketentuan

MengenaiPenyedian

danPemberian Hak Untuk Keperluan Perusahaan;

6. Peraturan Menteri Agraria Nomor 1 Tahun 1977 tentang Tata Cara Permohonan danPenyelesaiaan

PemberianHaka tasBagian Bagian Tanah Hak Pengelolaan sertaPendaftarannya;

7. Peraturan Pemerinqtah Nomor 40 Tahun 1996 tentangHak GunaUsaha, Hak GunaBangunan, Hak Pakai Atasanah;

8. PeraturanMenteriAgraria / KepalaBadan Pertamahan NasionalNomor 9 Tashun 1999 tentangTata CaraPemberian dan PembatalanHak Atas Negaradan TanahPengelolaan.

Ada sangkut pula adajuga subjek HakPengelolaan bahwa didalam Pasal 2 Ayaqt 4 Undang - undang Pokok Agraria subjek Hak Pengelolaan itu adalah 
Hasni \& Steven Ouddy

Volume 17, No. 2, Oktober 2019

Perlindungan Hukum Terhadap Pemegang...

daerah wilayah swantantra dan masyarakatt hukum adat. Subjek dalam Hak Pengelolaan pada Penjelasaan Umum II angka 2 dalam UUPA diuraikan mengenai pemberian pengelolaan HakMilik, HakPakai dan Hgb kepada suatu Badan Penguasa yang berupa departemen, jawatan atau daerah swatantra. Sebelumnya oleh sebuah adnya

PeraturanPemerintah Nomor8 Ta hun1953 yang menjadi subjek HakPengelolaan yang kemudian dikonversi menjadi HakPengelolaan adalah jawatan sebagai organisasi dari suatu kementrian dan daerah swantantra. Dengan demikian badan hukum swasta bukan sebagai subjek hak Pengelolaan. ${ }^{8)}$

Sehubungan dengan uraian sebelumnya, dalam kasus yang telah diadili di Pengadilan Mahkamah Agung, yaitu

\footnotetext{
${ }^{8)}$ Ramli Zein, Op.cit, hal. 53
}

Putusan Mahkamah Agung Nomor 3090/K/Pdt/2017, sebagaimana disebutkan para pihak dibawah ini:

Pipit Kurnia Wibisana, bertempattinggal di Jalan $P$. Jayakarta Nomor 64 RT010 RW0 10 Kelurahan Mangga Dua Selatan, Kecamatan Sawah Besar, Jakarta Pusat;

\section{Handoyo}

Layinanto, bertempattinggal di Jalan Raya Darmo Nomor 147-149 RT0 05 RW0 04 Kelurahan Darmo, Kecamatan Wonokromo, Surabaya;

Ny. Jong Ai Lin, Shinta Putih, Rony Patrice Putih, Julia Patrice Putih, Tolly Patrice Putih, Para Ahli Waris Tusaman Putih, berdasarkan Akta Keterangan Waris Nomor 7/VI/2004 tanggal 18 Juni 2004 yang dibuat di hadapan Hustiati, S.H., Notaris di Jakarta, semuanya bertempat tinggal di Jalan P. Diponegoro Nomor 14, Medan;Dalam hal ini semuanya 
memberikan kuasa kepada Para Advokat pada "Teguh Samudera \& Associates" beralamat di Kramat Raya Nomor 5, Perkantoran Maya Indah F12,Senen, Jakarta Pusat, berdasarkan Surat Kuasa Khusus tanggal 28 Juni 2016;

Kasus yang dipakai Penulis sebagai studi kasus pada karya ilmiah ini, yaitu Putusan Mahkamah Agung 3090/K/Pdt/2017, dimana Awal mulanya kedua belah pihak telah membuat akta Perjanjian Penggunaan tanah Industri (PPTI) Nomor 574 tanggal 26 Juni 1990 dan Perjanjian Nomor 576 tanggal 26 Juni 1990 dimana menurut ketentuan Pasal 19 butir (5) yang mementukan bahwa tergugat I PT KAWASAN BERIKAT

NUSANTARA akan memberikan prioritas persetujuan kepada tergugat II PT SUNTER AGUNG untuk perpanjangan penggunaan tanah apabila jangka waktu
HakGunaBangunan berakhir sesuai dengan Undang - Undang.

Dalam kasus ini, perpanjangan dan pembaruan sertipikat HGB ini mengalami ketidaksesuaian dengan aturan yang ada yaitu ada di Pasal35 Ayat1 dan 2Undnang - undarng PokokAgraria. HGB itu bisa dikasihkan dalam waktu dengan jangka waktu paling lama 30 tahun atas permintaan si pemegang haknya dan denga $n$ mengingat ke perluan serta keadaan $\mathrm{b}$ agunan bangunannya, dan mengenai jangka wakt $u$ itu bisa untuk diperpanjang dengan waktu paling lama dua puluh tahun

Gugatan tersebut kemudian dikabulkan oleh PengadilanNegeri dengan Putusan Nomor 230/Pdt.G/2014/PN Jkt.Utr. dan dibatalkan oleh Pengadilan Tinggi Jakarta dengan Nomor 647/PDT/2015/PT.DKI., sampai akhirnya dikuatkan oleh Mahkamah Agung dengan 


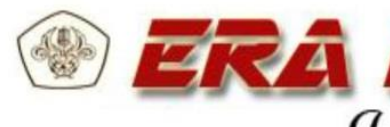

Gurnal Glmiah G/mu Glukum

Volume 17, No. 2, Oktober 2019

Putusan Nomor 3090 K/Pdt/2017.

Oleh karena itu, Penulis ingin mengkaji lebih lanjut mengenai Analisa Mengenai kewenangan si pemilik sertiqpikat HakGunaBangunan buat Mem per panjang dan Mem per baru i Hak Guna Bangu nan di sebuah atas yang itu adalah HakPengelolaan karena kalo Berdasarkan yang di liat d latar belakang iyu, Penu lis tertarik buat me laku kan kajian lebih lanjut dan menuangkannya dalam proposal skripsi yang berjudul "Analisa Mengenai perlindungan hukum Pemegang Sertipikat HakGunaBangunan Untuk Memperpanjang dan Memperbarui HakGunaBangunan di atas HakPengelolaan”.

\section{B. Perumusan Masalah}

1. Bagaimana kewenangann pemegangsertipikat HGB untuk memper panjang ataumemperbarui HGB di atas HakPengelolaan?

2. Bagaimanakah perlindungan hukum Pemegang HGB di
Hasni \& Steven Ouddy Perlindungan Hukum Terhadap Pemegang...

atas Hak Pengeloqlaan yang telah habis jangka waktunya tetapi masih menempati tanahdanbangunan?

\section{PEMBAHASAN}

A. Kewenangan Pemegang sertipikat HGB Diatas Hak Pengelolaan Untuk Memperpanjang Atau Memperbaharui Haknya.

1. Pengertian Hak Pengelolaan dan Dasar Hukumnya

Hak pengeloqlaan menurut $\mathrm{R}$. Atang Ranoemihardja itu sebetulnya ha katas tanah yang dipunyai sma negara dan juga hanya dapat dkasihkan kepada badan hukum pemerintah atau pemerintah daerah baik dgunakaan buat usahany pribadi maupun untuk kepernitingan pihakketiga. ${ }^{9)}$ istilah hak pengelqoaan ini satu diantqar jenis hakhak ats tanah samasekali sd tidak ada disebut didalam undangundang pokok agrarian nomor 5ta hun1960 istilah hak pengelo1laan demikian pula pen

\footnotetext{
9) Ramli Zein, Op.cit, hal. 53
} 


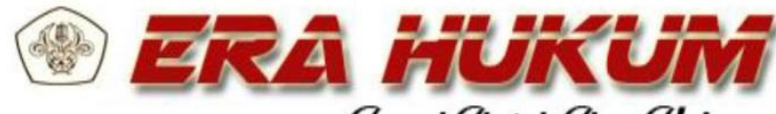

G)urnal GImiah G/mu Glukum

Volume 17, No. 2, Oktober 2019

gerti an dan lua snya itu ada dilura ketentuan uupa menerut a.p Psrilindungan istilah hak pengelolaan itu pertama kali tersebut di dalam PMA Nomor 9 tahun1965 yang mengisisikan ttg hak penguasaan atas tanah negara dan kebijaknaan dan selanjutnya maka mengenai hak penguasaan itu yang dijelaskan di konversi menjadi Hak Pengelolaan yang dituangkin di dalam Pasal 5 huruf (a) dan Pasal 6 PeraturanMenteriAgra ria Nomor 9 tahun 1965, berjalan selama tanah tersebut digunakan untuk keperluan oleh itu instansi yang bersangkkutan. ${ }^{6)}$

Asanya ketentuan yang di Pasal

6 dari PMa Nomor 9Tahun1965 tersebut, dengan tegas mengatakan bahwa merencanakan pengutukan dan pengqunaan tanah, yang mendukung pelaksanaan tugasnya serta menyerahakan bagian-bagian dari tanah, yang masing-masing luasanya maksimum $1000 \quad \mathbf{M}^{2}$

10) Ramli Zein, Op.cit, hal.49
Hasni \& Steven Ouddy Perlindungan Hukum Terhadap Pemegang...

kepada pihak ketiga dengan memberikan ha katas tanah tertentu yaitu Hak Pakai. ${ }^{11)}$

Kalo kita liatin dari penjelasan mum II angka (2) UUPA di atas, maka bisa kita kasih simpulan karena kalao landasan hukum dari hakpengelol aan di dalam UUPA, telah disinggung oleh Penjelasan Umum I I angka2 UUPA namun hukum materiilnya berada di luar UU PA Pasal2 ayat 4UUPA telah memberik1an kemungkianan untuk mem beri kan untuk suatu haky baru yang dulu namanya sendiri gaada, delegasi itu sebenarnya merupaka hak dan wewenqang pelaksanaan hak menguasai qegara kepada daerah-daerah otonom dan masyarakat hukum adat. Penjelasan Umum II angka (2) yang juga menyebut Pasala 2 ayat (4) UUPA, juga menyatakan ada kemungkinan bagi negara untuk memberikan tanah yang dikuasai negara dalam pengelolaan suatu badan penguasa

\footnotetext{
11) Nurhasan Ismail, Perkembangan Hukum Pertanahan Pendekatan Ekonomi dan Politik, (Jakarta: Huma,2007), hal. 245.
} 


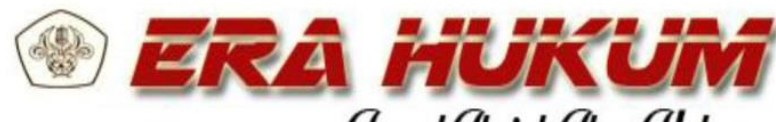

G)urnal GImiah G/mu Glukum

Volume 17, No. 2, Oktober 2019

(departemen, jawatan, atau daerah swatantra) untuk dipergunakan bagi pelaksanaan tugasnya masingmasing. Untuk delegasi wewenang pelaksanaan Hak Menguasai Negara itu, oleh peraturan yang ada disebutkan sebagai "Hak Pengelolaan".

Istilah "tanah yang dikuasai Negara" dengan merujuk kepada ketentuan Pasal 2 UUPA, berarti tidak hanya tanah yang belum diberati dengan sesuatu hak yang dipunyai oleh seseorang atau badan hukum, melainkan pula termasuk tanah yanh sudah diberati dengan suatu hak tertentu. Hal ini bisa disiqmak dalam enjelasan imum IIangka 2 UU PA yang menyatakan bahwa ada juga mengenai kekusaan negara yang maksud nya itu sebetulnya bisa mengenai semua bumi air juga ada ruangangkasa, jadi mau yang sdh di Haki oleh sesqrang atau juga yang tidak. Kekuasaan Negara menegenai tanah yang sudah mempunyainya untuk menggunakan haknya, sampai disitulah batas
Hasni \& Steven Ouddy Perlindungan Hukum Terhadap Pemegang...

kekuasyaan negara tersebut. Adaputn isi hak-hak itu serta pembgatasnya dinyqatakan dalam pasal 4 UUPA dan pasal-patsal berikutnya.

Mengenai Kekuasaan dari Negara atas tanahtanah yangs sydah tidak mempunyai dengan sesuatu hak oleh dengan seceorang atau pihakp pihak lainnya adalqah luas dan penuh. Menurut Mohammad Koesno, ${ }^{8)}$ Penjelasanmum IIangka UUPA ini, terlihat kekuasaam negara digambarkan seolah-olah bukan sebagai dasar, akan tetapi menjadi berdampingan dengan hak perseorangan atas tanah. Tampak lebih menonjol pandangan hak individu yang disejajarkan dengan kekuasaan negara. Suatu pandangan yang sejajar dengan pandangan ajaran hukum kodrat yang individualistis.

Sungguhpun demikian, Penjelasan mumII angka2 UUPA di atas, dapat dijadikan pedoman bahwa istilah "tanah dikuasai negara" tidak

\footnotetext{
12) Mohammad Kusno, dalam Ramli Zein,
} op.cit., hlm. 38 . 


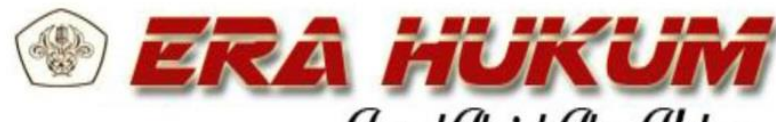

G)urnal GImiah G/mu Glukum

Volume 17, No. 2, Oktober 2019

berarti tanah yang dipunyai oleh negara. UUPA berpangkal pada pendirian, bahwa untuk mencapai aoa yang ditetapkan oleh Pasal =33 Ayat3 UUD 1945 (Amandemen ke IV), tidak perlu dan tidaklah pula pada tempatnya bangsa Indonesia ataupun negara bertindak sebagai pemilik tanah. Sesuai dengan pangkal pendirian di atas, perkataan "dikuasai" bukanlah berarti "dimiliki". Hal itu sekaligus pula menunjukan bahwa asas domein yang dikenal sebelumnya, telah ditinggalkan oleh UUPA

Ditilik dari sudut sejarah, seperti telah dijelaskan di atas, asal mula dari Hak Pengelolaan adalah "hak pengusaan" yang diatur oleh PeraturanPemerintah Nomor 8 tahun 1953 Pasal 1 huruf (a) menyatakan bahwa tanah neagra ialah tanah yang dikuasai penuh oleh negara namun Penjelasanumum

Peratuqran

Pemqerintah Nomor 8 tahun 1953 ini pada angka (1) jelas menyatakan bahwa tanah negara didalam Peraturan Pemerintah ini
Hasni \& Steven Ouddy Perlindungan Hukum Terhadap Pemegang...

dimaksudkan sebagai terjemahan dari istilah "vrijlandsdomein", yaitu tanah-tanah yang dimiliki dan dikuasai penuh oleh negara.

Hak Penguasaan yang diatur oleh Peraturan Pemerintah Nomor 8 Tahun 1953 inilah, kemudian dikonversi menjadi hak pengelolaan setelah berlakunya Undang-undang Pokok Agraria Nomor 5 Tahun 1960. Konversi hak penguasaan menjadi hak pengelolaan ini diatur oleh PMa Nomor 9 tahun 1965 didalemnya ada disebutkan jika apabila ada tanah negara yang sudah ada dik dalam Pasal 1, selain untk dipakaei sperti untuk kepentingan instansi-instansi itu sendiri, edengan adanya tujuan agara buat supaya dikasih dengan adanya sesuatu ada huk untuk si pihak ketiga, maka hak pengelolaan yang sudah disebutkan dalam Pasal 5 dan 6 yang telah lama berlangsung selama tanah tersebut dipergunakan untuk keperluan itu oleh instasi yang bersangkutan.

Hal yang sama juga bisa dilihat dari ketentuan yang ada di pasal 5 


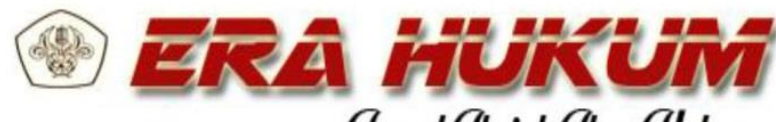

G)urnal GImiah G/mu Glukum

Volume 17, No. 2, Oktober 2019

yang udah disebut di oleh dalam pasal 2 pma nomor 9 tahun 1965 dengan tegas dalam pasal 5 mengatakan kalo adas ta nah tanahnegara yang ada di dalm ad maksud dalam pasal4 diats itu selain di per guna kan oleh instansi itu sendiri juga bisa di makqsud kan untuk dikasih denfnan suatu hak kepada si pihak ketiga,wewenang yang ada pada hak pqenloaaln seperti yang pernah ada dirumuskan di pasal 6 ayat 1 pma no 9 tahun 65 yang diulang kembali dalm pasal yang 28 pma namun kemudinn perumusan itu diubah dalam pasal 3 Pemegang hak pengeloqlaan selain berwenang untuk menggunaka tanah hak pengelolaan itu untuk adanya keperluan keperluan kalau ada pelaksanaan usahanya ia juga punya kewanangan pula untuk menyerahkan bagian bagian dari tanah hak pengelolaan itu kepada pihak ketiga dangan persyaratana tertentu bisa mengenai peruntukan ataupun jangka waktu dan juga bisa mengenai uangnya tapi dengan
Hasni \& Steven Ouddy Perlindungan Hukum Terhadap Pemegang...

syarat ketenttuan bahwa apabila hak yang atas tanah itu untuk pihak ketiga yang bersangkuraam dilakoni oleh pejabat yang punya kewenangan dlam hal ini sudh diatur di peraturan menterid lam neger npmor 6 tahun 1972

1. Objek Hak Pengelolaan

Dengan kita bepeggang pada pedoman yang ada fi Pasal 2UUPA, maka objel dari HakPenglolaan itu juga hsk ataq tanah lainnya adalah tanah yang dikuas oleh negara. Secara eksplisit kita lihat mengnai objek Hak Pengeloaan itu dapat disimak mengenai bunyi yang ada kecantum d PenjelasanUmum dua ayat dua UUPA yang talah di bahwa kekuasaan negra ats taneah yang tidak dipunyai dengan suatu hak oleh seseorang atau oihak lainya yang secara luas dan juga penuh, dengan demikian negara bisa kasih tanah yang demikian itu buat tanahnegara yang ssudah pernah diserahakan kepada suatu jawantan pada ssatt sudah ada berlakunya pp nomor8 tahun1953 ini makan meneteri dalam 
Hasni \& Steven Ouddy Gornal Glmiah G/mul Alukum

Volume 17, No. 2, Oktober 2019

neqeri punyahak mengadakan pengawasa an atas tanh tanqah tersebut hak pengua saan atas tanah tersbut ini lah yang kemudian oleh pma no 9- tahun195 5 di koversi kan menjadi hakpengelolaan.

Dari penjelasanumumI I angka 2diatas, objek hak pengelola an itu adalah tanah yang secara langsing dikuasa sama negara. Apabila ditelusuri sejarah dari Hak Pengusaan Tanah Negara yang datur sama PeraturanPemerintah Nomor 8 tahun 1953 ini me nyata kan, tanah negara ialah tanah yang dikuasai penuh oleh negara. Pasal 2 PeraturanPemerintah Nomor 8Tahun 1953ini kasih kjelasn kalo bahwa kecuali jika penguasaan atas tanahnegara dengan undsng-unddng atau per atuqran lain pada waktuberlaku nya peratusan pemerintahini telah di serah kan kepada suatu kementeriaqn jawatsan atau daerqah swntantra, maka penguasaan atas tanah negara ada pada Menteri Agraria, selanjutnya Pasal 3 Ayat (1) Peraturan
Perlindungan Hukum Terhadap Pemegang...

Pemerintahan Nomor 8 Tahun 1953

menyatakan bahwa didalam hal penguasaan tersebut dalam Pasal 2 Peraturan Pemerintah Nomor 8 tahun 1953 ada pada Menteri Agraria, maka ia berhak:

a. Menyerahkan Penguasaan itu kepada suatu kementerian, jawatan atau daerah swatantra untuk keperluan - keperluan tersebut dalam Pasal 4;

b. Mengawasi supaya tanah negara tersebut dalam sub a dipergunakan sesuai dengan peruntukannya dan bertindak menurut ketentuan dalam Pasal 8.

Untuk mengenai tanah negara dulu atau penah terjadi telah dilakukan penyerahan kepada suatu kement rian, jaw atan atau daerah swanta ntra pada saat di mulai nya berlakunya pp Nomor8 Tahun1953 ini, maka Mentreri Agr aria mempunyai wewenagn mengad akan pengawasanterhadap penggunaan tanah tersebut. Hakpenguasaan atas tanah negaraitulah yang 


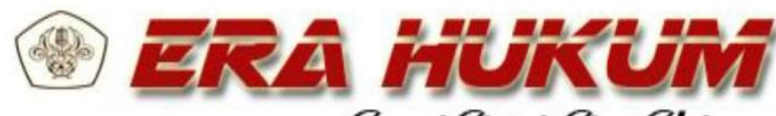

GIurnal G/miah G/lmu Alukum

Volume 17, No. 2, Oktober 2019

kemudianoleh pma Nomor 9 tahun1965 yang dikonversukan menjadi HakPengelolaan, jikatanah negaraitu selain di buat untuk ke penting an instani-insansi itu sendiri, di maksu dkan juga untuk bisa dikasihin hak kepada pihak ketiqa. Dengan begitu lah tanah negsra yan akan diserahkankepada suatu instansi selain akan dip erquna kan nya sendiri, juga supaya agar untuk diberikan dengan sesuatu hakkepada pihak ketia, dengan gitu menteri agraria tanahtanah tersebut akan di berei kan HakPengelolaan. ${ }^{13)}$

2. Subjek HakPengelolaan

Haka Pengeqolaan jika dipndang dari pndangan sebagai sebuah wakilan wewenang dari hakmenguasai oleh Pemerinah maka kalo liat Pasal 2Ayat4 UUPA. hak menguasai negara itu bisa buat di kuasak an kepada daeah - darreah swanqtantra dan masyarakat masyarakat hukum adat. Dalam penjelasm ymum II angka 2 di sebut kan pula atau mem berikan nya

\footnotetext{
13) Ramli Zein, op.cit, hal. 64.
}

Hasni \& Steven Ouddy Perlindungan Hukum Terhadap Pemegang...

dalam pengelolaan kepada suatu badan penguasa (departemn, Jawaqtan, atau daerahswantantra) untuk bisa digunakan buat pelasanaan tugss nya sendirisendiri

Di dalem alam kemerdekaan, masalah penguasaan atas tanah negara pada mulanya diatur oleh PeraturanPemerintah Nomor 8Tahun 19 53. Pasal 4 PeraturanPemerintah Nomor 8Tahun $19 \quad 53$ ini menyebutkan bahwa penguasaan itu bisa di serah kan kepada suatu kementrian atau jawata dan suatu daeraj swatatantra. Jawastan menurut Pasal1 hurufa PeraturanPemerintah Nomor8 Tahun 19 53adalah organisasi suatu kementerian yang berdiri sendiri. Daerah swantantra menurut Pasal 1 Hurufc PeraturanPemerintah Nomor8 Tahun19 53 ini, adalah wilaya yang dikasih hak buat meng atur rumah tang ganya secara mandiri. ${ }^{14)}$

Hukum Agraria Nasional membagi hak-hak atas tanah dalam 2 bentuk; Bersifat sekunder: hak-hak

14) Ibid,. hal. 65 
atas tana yang difat sementara.

Maksudnya adalah hak-hak tersebut dinikmati dalam waktu terbatas karena tanah tersebut milik pihak lain. a. HakGadai b. Hakusaha bagi hasil c. Hakmenumpang d. Hak menyewa atas tanah pertanian.

Bersifat Primer: hak-hak ata tanah yang bisa punya atau dikuasai secara langsung oleh se se orang atau badan hukum yang mempunyai waktu lama dan dapat dipindah tangankan kepada orang lain atau ahli warisnya. Hakmilik atastanah Hakgunausaha, Hakgunabangunan, Hak Pakai. Berdasarkan keterangan diatas yang terkait dengan penulisan skripsi ini adalah Hak Guna Bangunan yang akan dipaparkan sebagai berikut,

Hakgunabangunan seenernya punya akan makna yang berisi yaitu hak yang digunain buat mendirikan ataupun memiliki sebuah bangunan diatas tanah yang bukan punyanya yang pastinya dengan jangkawaktu terbatsaa atau terukur sebagai suatu tentang ha katas sebuah tanah maka hgb memberi kuasa kepada yang memiliknya untuk bisa gunain tanah yang ber sangkut an tu berlainan dengan hgu maka waktu menggunakan tanah nya juga bukan untuk dipake untuk usaha semacam untuk pertanian melainkan di guna kan buat mendirikan sebuah bangunan oleh sebab dari itu maka sebenernya tanah negara apa tanah per orang an atau sebuah badanhukum bisa saja dengan hgb.Adapun khusus mau untuk di per untuk kan membangun sebuah banguan, mengenai hal itu namun bukan mempunyai sebuah arti bahwa atas tanah itu yang punye halaman gaboleh bercocok tanamana atau punya kolam ikan. Asal tujuan akan penggunaan tamaj uang pokok itu buat membangun bangunan sebagaimana halnya

Hak Guna Bangunan juga sbsentulna bisa aja dialihkan kepada pihak yang laun. Peralihan HakGunaBangunan terjadi karenajualbeli, tukarmenukar, penyertaan dalammodal, hibah, danpewarisan hapusnya 


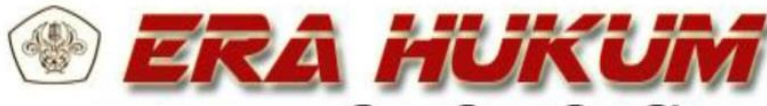

GIurnal G/miah G/lmu Glukum

Volume 17, No. 2, Oktober 2019

HakGunaBangunan yagn ada dalem Pasal35 PeraturanPemerintah

Nomor40 Tahun19 96 di sebut in sebab nya:

a. jangka waktunya udah habis yang karena ditetapkan di keputusan pemberian atau perpanjangannya yang ada di dalam waktu pemberian perjanjiannya;

b. pejabat yang berwenang melakukan pmbatalan atas hak tersenut kepada pemegang sertipikat karena

1) kewajibam nya udah ngga dipenuhi secara penuh maupun sebqagian, ataupun melanggar ketentuan yang ada yang uda jadi ke wajib an si pemegang Sertipikat hakgunabangunan

2) tidak ter penuh inya syarat dan kewajiban yang ada di perjanjian yang $\mathrm{d}$ iberi kan hakpengelolaan untuk sipemilik SHGB

\section{Hasni \& Steven Ouddy} Perlindungan Hukum Terhadap Pemegang...

3) ada putusan dari pengadilan yang sudah berceakuatan hukum terap.

c. Dilepanjan secara begitu saja atau sukarela oleh si pemegang shgb;

d. dicabut karena sudah diatur di UU nomqr 20 Tahun 1961 tentang pencabutan Hak-hak atas tanah ;

e. dibiarkan sampe terlihat kumuh atau bisa disebut di telantar kan;

f. musanah tana hnya karena suatu sebab.

Bagi pemegang shgb dalam waktu satu tahun benar benar tidak memenuhi syarat maka kuasa atas hak guna bangunan itu berakhir begitu saja

Dengan demiqkian berarti bahwa di dalam Pasal2 Ayat4 Undang undang pikok Agrari subjek yang ada d atas hak pengelo1laan itu adalah daeraqh swantaqntra dan masyarakqat hukum adaqt, yang selanjutnya ditangkan dlam Penjeladsan Unum II angka (2) UUPA dijelaskan subjek Hak. Bahwa 
berdasarkan Akta Perjanjian Nomor : 574, tanggal 26 Juni 1990 dan Akta Perjanjian No.576, tanggal 26 Juni 1990, Perseroan Terbatas (Persero) PT. KAWASAN BERIKAT NUSANTARA (tergugat I) sepakat menyerahkan penggunaan tanah kepada Tergugat II PT. SUNTER AGUNG selama 21 (dua puluh satu) tahun untuk dibangun pabrik-pabrik, untuk industri-industi yang tidak meng andung polusi berat danless liquid wasete, gudadnggudqang dan tempat pen ampung an containr, atas sebidang tanah kavling yang merupakan Adapun sebutan menganai nama atas hak tanah sehinga ada beberapa macam hak atas tanah hak tanah apa aja sebenernya semua itu mem beri kewenangan untuk bisa gunakan tanah itu untuk memenuqh kebetuhan yang dibutuhkan. Pada dasar nya pemakaian untuk sebuah tanah itu punya batas yaitu hanya kepada untuk sebuah tujuan pertama untuk usaha missal bisa untuk bertani, kolam ikan dan yang ke dua nya bisa digunakan untuk membangun sebuah bangunan maka dengan sperti itu mengingat dalam masyarakat yang semakin maju dan modennr ini makak dipermudah untuk pengenalananya ada hakmilik, hak gunausaha, hak gunabangunan, dan hak pakai

Menurut surat departemen pertaniandan agrarian apa yang elah ditentukan dalam pasal ini atas berlaku juga terdapat hgb yang dipunyai secara sama sama oleh pihak yang udah penuhin syarat dan yang belum penuhi syarat hgb ini tidak bisa hanya hapus begitu saja karena merupakan kepunyaan bersama dalam waktu tahun kalo si pemilik tidak memenuhi syarat maka sudah se harus nya melepadskan hak tanahnya menjdadi sebuah tanah negara berbeda dengan hak pakei yanag memiliki pengertian sebagai hak utnuk pakai danatau memungut hasil dari tanah itu yang bisa langsungdi kuasa oeeh negara atau suatu tanah punya orang laen yang memberi wewenang dan kewajiban yang telah diperpinjangakan yang akhirnya dituang dalam perjanjian

Nah dapat dilihat kalau meleihat ke pasal 41 maka hak pakai itu sebetulnya 
ERA HURUNA

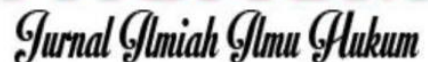

Volume 17, No. 2, Oktober 2019

punya arti atau kumpulanpengertian sebagai hakkah yang dikeqnal di hukum tanah dengan berabagai naam yang semuanya dikit akan per beda aan dan mengenai jangka waktu sebagaimana sudha diutara ka diatas dalam praktek biasanua hak pakai diberikan waktu sepulu taon oleh pemerintah karena biasanya hak pakai itu di per untuk an bagi pengunaan yang sifatnya sebentar maka tidak ada jaminan untuk bisa di perpanjang lagi kalau jangka waktunya selesai biasanya untuk hak pakai pengaturan mengenai tentang luas tanahnya tidak me lebihi dari angka dua ribu meter perrsegi dan juga punya jangka waktu yang sebatas se puluh tahun dan yang berhak mengatur adalah gubenuratau kepa la daerha shak pakaidiberikan dengan surat kepurtusa pemberian hak oleh yang punya wewenan Syarat ketentuan untuk melakukan per panjang an dan pem baha ruan HakGunaBangunan menurutpasal dua enam PPNo 40tahun 1999 adalah:

a. Yang ada dalam pasal 22 hak guna ibangunan itu bisa diperpajang atau
Hasni \& Steven Ouddy Perlindungan Hukum Terhadap Pemegang...

dipebarui sertipikatnya asalkan bisa memenuhi persyaratan yang ada yaitu tanahnya bisa dipergunakan denagn baik bagaimana sesuai keadaan dipat dan tujungannya Pasal 19; tanah itupun harus tersebut masih sesiaai decaen rtrw yang bersangkutan.

b. Hgb yang atas tanah Hak Pengelolaan itu bisa saja buat di per panjangatau di baruin atas mintanya si pemegang sertipik hgb setelah dia dapat per setuju an dari si pemegang Hak Pengelolaan

1. Ciri ciri

Kalau dite laah pasal - pasal UUPA, maka akan ditemui ciri ciri HakGunaBangunan sebagai berikut: $^{15)}$

a. HakGunaBangunan tergolonhak yang kuat yangartinya tidakmudah hapus dan mudah dipertahankan terhadapgangguan pihak lain. Olehkarena itu, HakGuna Banguna termasuk salah satu hak yang wajib di daftar (Pasal 38 UUPA dan Pasal

\footnotetext{
${ }^{15)}$ Effendi Perangin, Op.,Cit hlm 259
} 


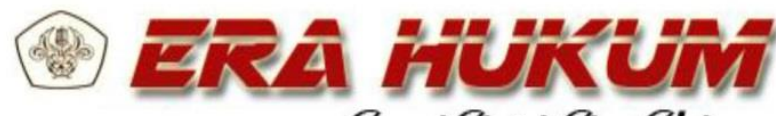

G)urnal GImiah G/mu Glukum

Volume 17, No. 2, Oktober 2019

10 Peraturan Pemerintah no. 10 Tahun 1961)

b. Hgb bisaberalih, artinya dapat di waris oleh ahli waris yang empu nya hak (Pasal 35 Ayat 3)

c. Hgb jangka waktqunya terbatas, arti nya ada suatu waktuwaktu pasti berakhir (Pasal 35 Ayat 1 dan 2)

d. Hgb dqapat dijadikan jaminan utqang dengan cara di bqbani hak tanggungan; hipotek atau credietverband (Pasal 39)

e. Hgb dapat di alih kan kepada pihak lain pake cara dijual ato di tukarkandengan bendalain, di hibah kanatau di berikan dengan wasiat (Pasal 35 Ayat 3)

f. Hgb dapat juga di lepas kan oleh si pemilik hingga tananya menjadi tanahnegara (Pasal 40 huruf c);

g. Hgb hanya dapat di berikan untuk keperluaan pem bangunan bangunanbangunan

2. Jangka Waktu Hak Guna Bangunan Hak guna Bangunan jangka waktunya ada batas. Hal itu dapat di lihat di dalam Pqasal 35 Ayat (1) dan (2) Uupa mengataajan
Hasni \& Steven Ouddy Perlindungan Hukum Terhadap Pemegang...

HakGunaBangunan itu bisa aja sampai dengan 30 tahun atas permintaan sipemegang atas hak nya itu dan juga kalo dalam keadaan tertentu dan juga ada keperluan maka didalam unadng undang, jangka waktu itu bisa atau dapats saja untuk di per panjang dengan waktu yang bisa sampe duapuluh tahun. $^{16)}$

3. Terjadinya HakGunaBangunan karena Perjanjian

$\mathrm{Hgb}$ bisa aja di berik an oleh seorang pemilik tanah. Dalam hal yang demikian maka HakGunaBangun an itu terjadi gara perjanjian antara si pynya tatanah yang ber sangku tan dengan orang yang bakal memperoleh hak tersebut. Perjanjian yanqg diadakan dengan maksud untuk menciptakan hak itu harus berbentuk otentik dan menurut Pasal19 PeraturanPemerintah Nomor1 OTahun 1961 harus di bukt ikan dengan aktay ang dibuat oleh dqan di hadap an PPAT.

4. Pembebenan $\mathrm{HGB}^{17)}$ 
Hasni \& Steven Ouddy Perlindungan Hukum Terhadap Pemegang...
Hgb itu pada dasar nya tidak dapat dibebani ha katas tanah lainnya, yang bertujuan agar pemegang hak baru itulah yang bisa men diri kan bangunan itu diatasnya dan memiliki bangunan tersebut. Kalau hgb dibebeani dengan hak tanah lainnya, maka tanahnya di serah kan dalam penguasaan fihak yang dikasi hak itu mengigat bahwa hgb adalah suatu hakuntuk men diri an bangunan dan bisa punyai bangunan diatas suatu bidang tanah sesuai pasal3 5 ayat 1maka akan ber tenta ngan dengan sifat dan tujuan pemberian hakgunabangunan itu jika misalnya tanah yang bersangkutan disewakan atau diserahkan dengan hak pakai kepada fihak lain dalam keadaan kosong, dengan niat agar pihak penyewalah itulah yang mendirikan bangunan diatasnya dan memiliki bangunan tersebut. Lain halnya jika yang disewakan itu hak guna bangunan yang sudah ada bangunannya. Dalam hal ini demikian objek persewaan bukannlah tanahnya melainkan bangunannya
5. Hapusnya Hakgunabangunan ${ }^{18)}$

Hgb bisa aja dapat hapus ya karena: a. emang jangka waktunya habi, b. disetop sebelom jangkawaktunya habis, atau bisa karea satu lain hal per syarat an yangtidakdipenuhi; $c$. dilepaskan begeoti aja sma pemegang haknya sebelum jangkawaktunaberakhir; dicabutuntuk keperntinganumum; e. ditelantarkkan; f; tanahnymusnah; g. ketentuan yang dituang di pasal 36ayat2

Penjelasan mengenai hapusnya Hak Guna Bangunan sama denagn uarian pada hapusnya hak milik dan hak guna usaha degan penyesuuaiann yang seperlunya. Dengan terhapusnya hak guna angunan maka tanahnya yang bersangkutan kembali pada penguasaan penuh dari yang bersangkutan kembali pada pengguasan penuh dari pemilik tersebut "hak milikna jad balik penuh lagi”. Jika diadakan pencabutan hak

${ }^{18)}$ Ibid., hlm. 285 
Hasni \& Steven Ouddy Gornal Glmiah G/mul Alukum

Volume 17, No. 2, Oktober 2019

untukkepentinganumum, maka tentunya hak milik atas tanah yang bersangkutan dicabut juga dengan demikaan maaka tanah akan menjado tanah negara

B. Perlindungan Hukum yang ada bagi sipemegang Hakgunabanagunan Diatas Hak Pengelolaan yang uda abis jangkawaktunya

Sesuai dengan fungsi Pasal 6UUPA yang berbunyikan "semua hak atas tanah mempunyai hak sosial" yang mempunyai makna:

1. Pemegang hakwajib menggunakan tan ah sesuai dengan peruntukan tanahnya, jadi kalau hgb harus didirikan bangunan diatasnya dan ditempati oleh pemegang haknya.

2. Kalau ada per tentan gan antara ke pentin gan umum dengan kepentingan perorangan maka pasti yang dimenangkan kepentingan umum tetapi tidakIII. PENUTUP boleh serta merta mengabaikan kepentingan perorangan.
Perlindungan Hukum Terhadap Pemegang...

Berdasarkan uraian diatas maka kaitan dalam kasus skrips ini memenuhi isian makna yang pertama, sehingga seharusnya diberikan izin dalam memperpanjang Hak Guna Bangunan sebagaimana diatur dalam pasqal 25 Ayat 1 dan 2 PP Nomor 40 Tahun 1996 yang berisikan:

1. Hgbangu nan yang ada diatur di dalam Pasal 22 di kasihkan untuk jangka waktu paling lama tiga puluh tahun yang dimana bisa untuk diperpanjang lagi untuk jangka waktu bisa untuk paling lama dua puluh tahun.

2. Dan juga cedudah jangka waktu Hgb itu habis dan perpanjangannya sebefaimaan diatur di dalam ayat yang satu berakhir, kepada pemegang yang yang lma bisa untuk hak itu dapat diberikan kembalik atas pembaharuan Hakgunbangunan di atas tanah yang sama. 


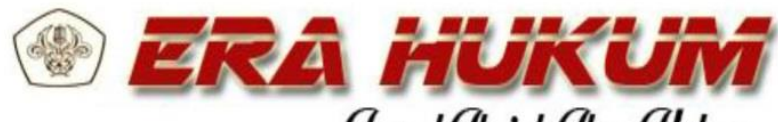

G)urnal GImiah G/mu Glukum

Volume 17, No. 2, Oktober 2019

Dari hasil jabar dan analisa yang uda diutaraikan, bolih untik ditariqk kesimpulan bahwa kewenangan yang ada pada pemegang HGB atas tanah HGB di atas hak pengelolaan untuk per panjang an nya atau mem perb aharui haknya adlaah ada. Pihak ketiga selaku pemegang Hakguna bqangunan dapat memperpanjang atau memperbaharuinya haknya. Hal bisa diliat berdasarkan pada Undang Undaqng Pokqok Aqgraria Pqasal 35 Ayat yang men yata kan Hakgunabangunan itu punya oengeritan sebahia hak untuk mendirik an dan mem punyai bangunqan-banqgunan atas tnah yangbukan miliqknya pribaqdi, dengan jangkawaktu paling lama tiga puloh tahun. Klo ada per minta an dari si pemegang hak dan dengan meng ingat keperluaqn serta keadnaan banguqnan-bangqunannya, jangka waktu tersebut dapat diperpanjang dengan waktu paling lama dua puloh tahun perlindung an hukum yang bisa dikasih bagi pemegang sertipikat
Hasni \& Steven Ouddy Perlindungan Hukum Terhadap Pemegang...

perlindunganhukum yang bisa didapat ataujuga diberik an oleh per undang an dan perjanjian dalampasal25 PPNomor 40 Tahun19 96 yang berisikan: hgb yang telah dituang dalam Pqasal 22 itu akan diberik an sampai untuk jangkawaktu paling lama tiga puluh tahun yang dimana dapat diperpanjansg untuk jangkawaktu paling lama dua puluh tahun dan sesudah itu ada jangka waktu HGB dan per panjanga nnya sebagai-mana dimaksud dalam ayat (1) berakhir, kepada bekas sipunya hak bisa dikasihin pem baharu an Hgbangunan di atas tanah yang sama.

\section{B. Saran}

me liat kesimpulandi atas adapunsarans aran yang dapat diberikan yaitu perlunya dibuat perjanjian secara tertulis dihadapan notaris, antara para pihak apabila jangka waktu sertipikat HGB sudah mendekati masa berkahir agar para pemiliki sertifikat HGB diberikan izin untuk kembali menempati tanah tersebut. Agar 
pemerintah dapat membuat peraturan perundangan yang khusus adanya mengenai hgb yang ada di atas HakPengelolaan ini sehingga supaya bisa jadi pedoman untuk pihak pihak yang akan atau segera mempunyai kepentingan memanfaatkan atas tanha tanah tersebut.

\section{DAFTAR PUSTAKA}

\section{A. Buku}

Ruchiyat, Edy. Politik

Pertahanan Nasional

Sampai Orde Reformasi,

Edisi ke-2 (Bandung :

Alumni, 1999)

Harsono, Boedi. Hukum Agraria

Indonesia, Sejarah

Pembentukan UUPA, isi

dan Pelaksanaannya, Jilid

I. (Bandung: Citra

Aditya,1997

Ramli Zein, Hak Pengelolaan

dalam Sistem UUPA,

Cetakan ke - 1. (Jakarta:

Rineka Cipta, 1995, hlm.

61-68.

Nurhasan Ismail, Perkembangan

Hukum Pertanahan
Pendekatan Ekonomi dan

Politik, (Jakarta:

Huma, 2007)

Effendi Perangin, Hukum

Agraria Di Indonesia

(Jakarta: Rajawali

pers, 1991)

\section{B. Peraturan Perundangan-undangan}

Indonesia. Undang-Undang Dasar Negara Republik Indonesia Tahun 1945 (Lembaran Negara Republik Indonesia Tahun 1945 Nomor 5).

- Kitab Undang-Undang Hukum Perdata (Burgerlijk Wetboek)

. Undang-undang Nomor 5 Tahun 1960 tentang Peraturan Dasar - Dasar Pokok Agraria

Peraturan Menteri Agraria Nomor 9 Tahun 1965 tentang pelaksanaan konversi Hak Penguasaan atas Tanah Negara dan ketentuan - ketentuan tentangg Kebijaksanaan

- Peraturan Menteri Agraria Nomor 1 Tahun 1966 tentang Pendaftaran Hak Pengelolaa 


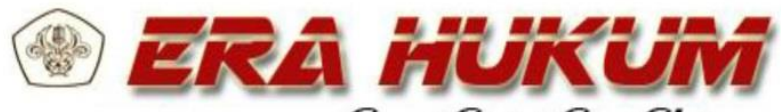

GIurnal G/miah G/lmu Glukum

Volume 17, No. 2, Oktober 2019

Peraturan Menteri

Agraria Nomor 6 Tahun 1972

tentang Pelimpahan Wewenang

Pemberian Hak Atas Tanah

\begin{tabular}{l} 
Peraturan Menteri \\
\hline Agraria Nomor 5 Tahun \\
1974 tentang Ketentuan - \\
Ketentuan \\
Penyedian dan Pembenai \\
Hak Untuk Keperluan \\
Perusahaan
\end{tabular}

$\begin{array}{lrr} & \text { Peraturan } & \text { Mentri } \\ \text { Agraria Nomor 1 Tahun } \\ 1977 \text { tentang Tata Cara } \\ \text { Permohonan } & \text { dan } \\ \text { PemberianHak } & \text { AtasBagian } \\ \text { BagianTanah } & \text { HakPenge } \\ \text { lolaan } & \text { sertaPendaft } \\ \text { arannya } & \end{array}$
. PeraturanPemerintah Nomor 40 Tahun 1996 tentangHak GunaUsaha, Hak GunaBangunan, HakPak ai Atas Tanah

\begin{tabular}{l} 
Peraturan Mentri \\
\hline AgrariaKepala \\
Pertanahan \\
Nomor 9 Tasional \\
tentang Tata Cara Pem beri \\
an dan Pem batalanHak \\
AtasNegara dan TanahPen \\
gelolaan
\end{tabular}

\section{Jurnal}

Fahamilla, Murambika. "Pelaksanaan Perpanjangan Hak Guna Bangunan Yang
Hasni \& Steven Ouddy Perlindungan Hukum Terhadap Pemegang...

telah Habis Masa Berlakunya Berdasarkan Peraturan Pemerintah Nomor 40 Tahun 1996 di Kabupaten Sleman" 12 Januari 2017, hal 1

Syafira Mahila dan Nur Fauzia, "pelaksanaan perjanjian Sewa Tempat Usaha Antara Pedagang Angso Duo dengan Pemerintah Daerah Kota jambi", Jurnal Ilmiah Universitas Batanghari Jambi, volume 10 No.1 Tahun 2010, Hal. 41. 